\title{
Efficiency in an Intensive Energy Industrial Consumer
}

\author{
J. Galvão ${ }^{1,2}$, A. Nabais ${ }^{3}$, M. Galvão ${ }^{4}$, J. Candeias ${ }^{1}$, T. Pereira ${ }^{1}$, J. Ramos ${ }^{2,5}$ \\ ${ }^{1}$ Department of Electrical Engineering; Polytechnic of Leiria, 2411-901 Leiria (Portugal) \\ Phone:+00351 244820300, e-mail: jrgalvao@ipleiria.pt \\ ${ }^{2}$ R\&D Unit, Institute for Systems Engineering and Computers /INESCCoimbra (Portugal) \\ ${ }^{3}$ ECOBIE - Engenharia Lda, Leiria (Portugal); adelino.nabais@ecobie.pt \\ ${ }^{4}$ ISTécnico/Lisbon Technical University, 1049-001 Lisboa (Portugal); mafaldagalvao@ tecnico.ulisboa.pt \\ ${ }^{5}$ Department of Mechanical Engineering; Polytechnic of Leiria, 2411-901 Leiria (Portugal); joao.ramos@ipleiria.pt
}

\begin{abstract}
Energy efficiency actions were made in a glass production industry such as reduction in the energy consumption that will reduce greenhouse gas emissions. All measures were applied regarding European Union- EU guidelines and legislation.
\end{abstract}

Key words Energy efficiency, industrial heat, photovoltaic system, sustainability.

\section{Introduction}

To reduce greenhouse emissions a high diversity of laws and directives has been released with the objective of boosting legislation in EU countries supported by the circular economy concept. It is necessary to combine efforts that will lead to the achievement of several targets, such as those set out in the "Roadmap for moving to a competitive low carbon economy" [1]. To be able to convert the linear economy into a competitive low carbon economy, the EU must reduce their internal emissions for $80 \%$ by 2050 compared to 1990 . In this context it should be noted that the industry and the intensive energy consumer process sector, in particular the glass industry, will have to play a significant role to achieve this goal.

\section{Methodology, Objectives and Case Study}

The increasing energy consumption is a major concern for intensive energy industrial consumers, most of them are exporters companies that assume an increase in environmental pollution in particular in terms of greenhouse gas emissions (GHG) to the atmosphere. An energy audit was carried out in a glass production industry to detect opportunities for energy rationalization actions in the company (Figure 1). Several energy analyzers were installed in distributions electrical border to understand how the consumption is done by the production line machines and the glass production furnace. One infrared thermographic camera was also used to collect information about heat leaks.

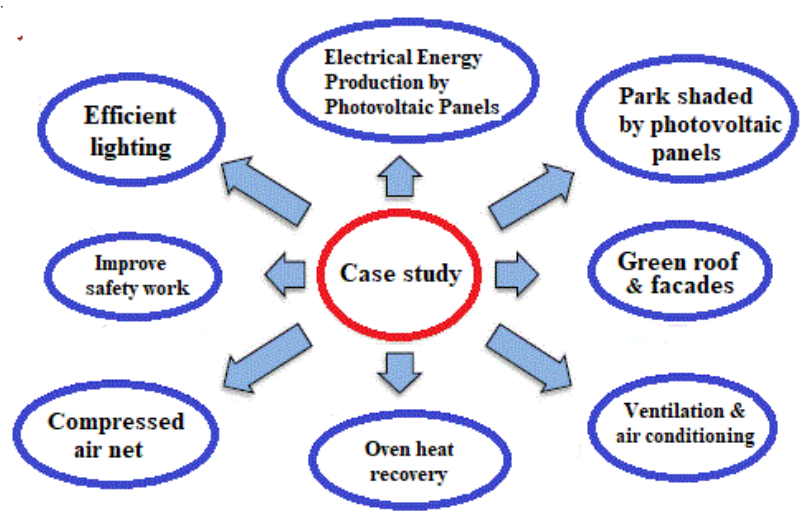

Fig.1 Opportunities for energy rationalization in the glass industry

The main objective is to find as many solutions as possible so they can be applied to the case study industrial glass company, in order to promote their sustained growth.

Another objective through the Energy Management System (EMS) which is an energy efficiency tool applicable in industry, services or in any type of organization regardless of its size can be certified by ISO 50001. The ISO 50001 standard aims to define the requirements for an EMS, which enables organizations to establish the necessary systems and processes, with the ultimate goal of improving energy consumptions and enabling reduction costs associated with the energy bill [2], [3], [4].

The company's guidelines for implementing a culture among all energy conservation workers is an objective to be achieved, but it takes some time to the results [5].

The case study is based on the production of white glassware dedicated to the production of calcium-sodium glass founded in 1996 located near Leiria/Portugal. The production process has several stages, from raw material to the final product Figure 2 [6].

To satisfy the factory needs of electrical power, there is an electric transformation equipment with a power of 400kVA, outside its facilities.

Currently the company has in production area 3 pickup robots, glass presses, automatic presses, a machine (ISsingle section), an automated select bottles system including a robot and two quality control chambers. 
These equipments produce more product to its customers, are more diversified and can enter in new markets such as:

- Building materials (glass tiles, tiles and bricks);

- Packaging glass (bottles and jars for food and cosmetics);

-Technical lighting (ceiling lights, spotlights and headlights).

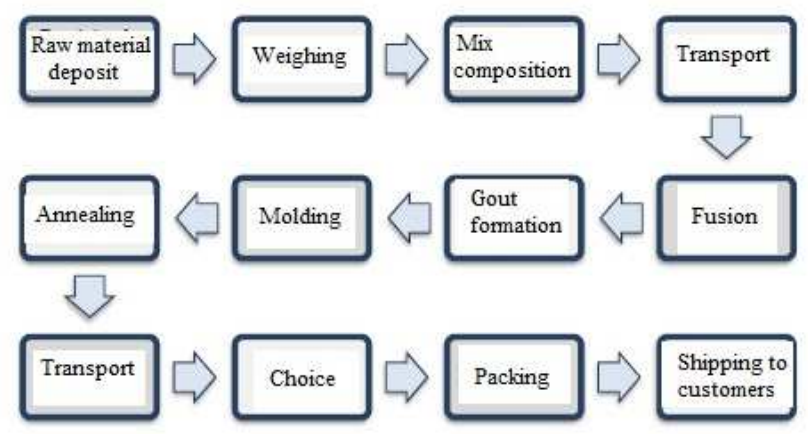

Fig. 2 Production Process Stages

\section{Energy Audit and Data Analysis}

One of the first tasks performed was the analysis of energy consumptions of electricity, gas and fuel from the previous three years.

Given the overall consumption of electricity (Figure 3), it is important to know the electrical equipment consumptions, such as air compressors and annealing tunnel (Figures 4, 5).

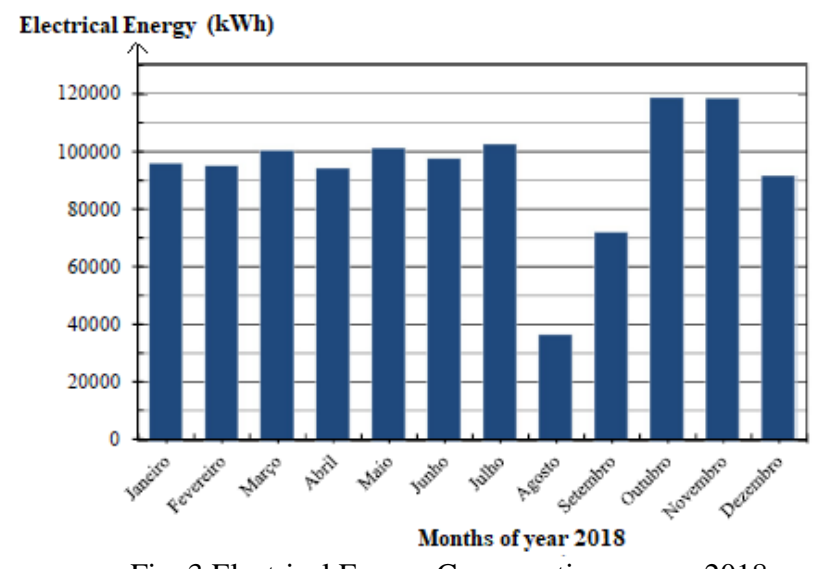

Fig. 3 Electrical Energy Consumptions - year 2018

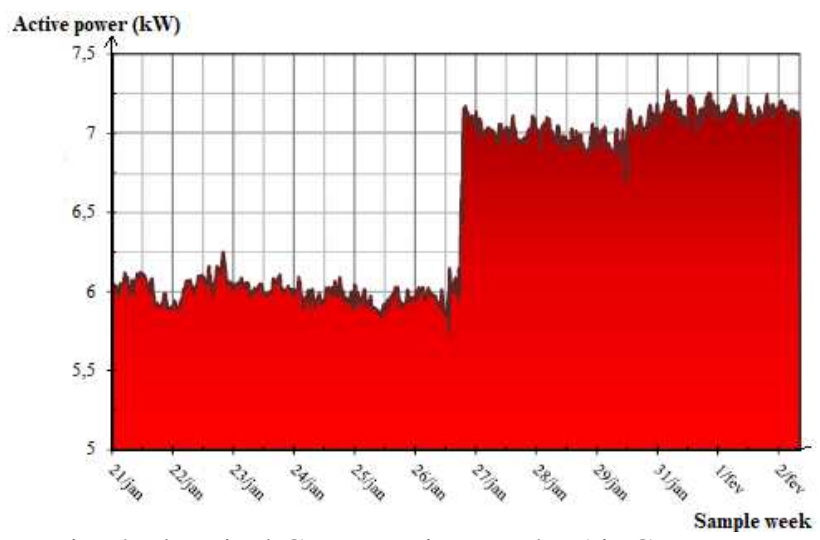

Fig. 4 Electrical Consumptions at the Air Compressors

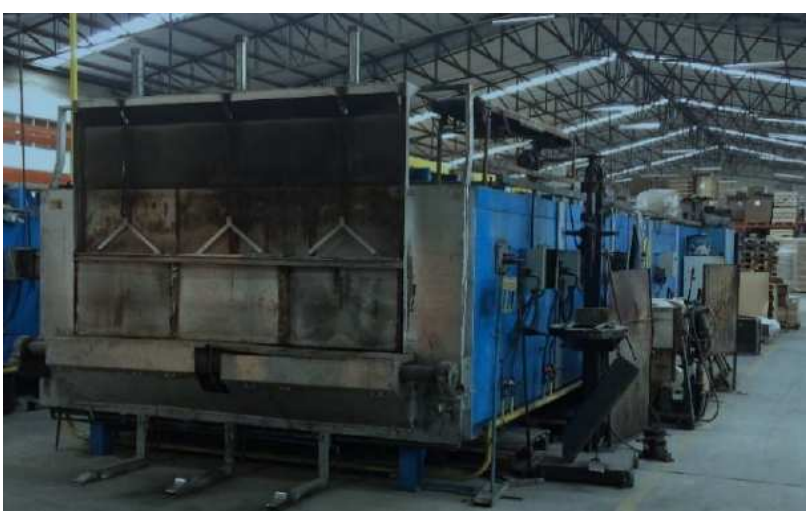

Fig. 5 Annealing Tunnel General View

By analysing Figure 6 it can be concluded that the energy consumption does not have large oscillations despite the summer vacations.

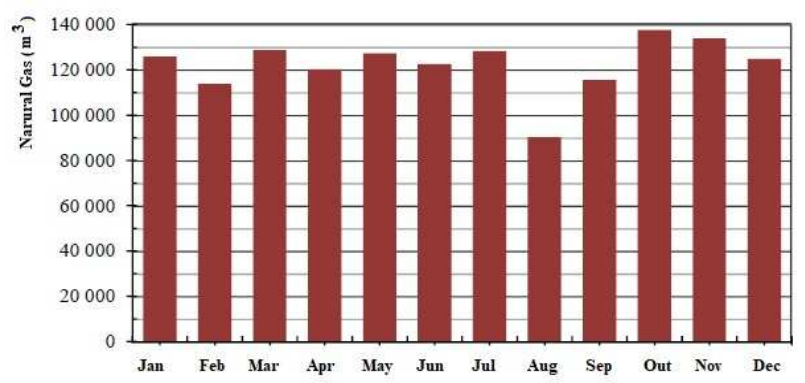

Fig. 6 Natural Gas Consumption - year 2018

More data was collected by infrared thermographic camera during the work performed at the company [7].

\section{Results}

Keeping in mind the actions developed in Figure 1 only in this section it will be considered this areas:

- Electricity production by photovoltaic system;

- Green roofs in the production sector;

- Heat recovery in the oven chimney.

To develop the photovoltaic production system several simulations were done with the PVSyst software. Figure 7 represents the input data where the column in the graph is similar to the Figure 3 (electrical energy consumptions) [8].

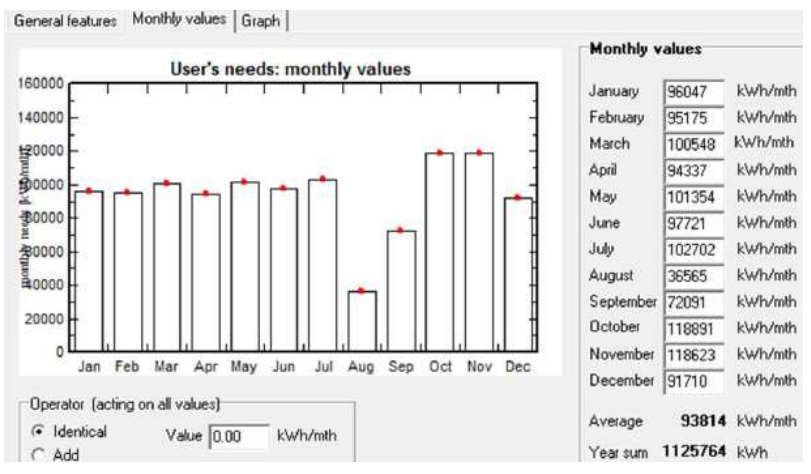

Fig. 7 Input Data for Simulations

In order to validate the design performed in PVsyst, the online platform Sunny Web Design was also used [9]. 
The results obtained in the Sunny Design Web are in agreement with the results obtained in PVsyst.

After selecting equipment to be installed, the cables were calculated, as well as the interconnection of all proposed components in the system, like the protective equipment and ground connections. To do this a spreadsheet was used to list the cables and protections of the panels system. For the calculations of the protective equipment cutting gauges, the technical rules for low voltage electrical installations were concordantly to the Portuguese legislation.

Through PVSyst software it was simulated the optimized result for this type of self-consumption energy production.

The relative impact of the electricity generated by the photovoltaic system in relation to the existing electricity consumption is represented in Figure 8.

The investment payback of the photovoltaic system was about 5 years.

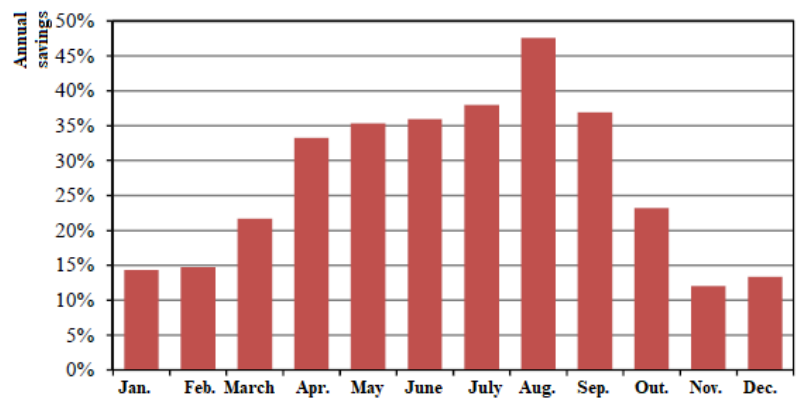

Fig. 8. Monthly Impact of Photovoltaic System in Electricity Consumption

There are two areas to install the photovoltaic system. One is on the top roof of the company, the other is in the car park like the model shown in Figure 9. This 3D draw was built with the Sketchup software. There is also a car charging station for electric mobility cars in the company.

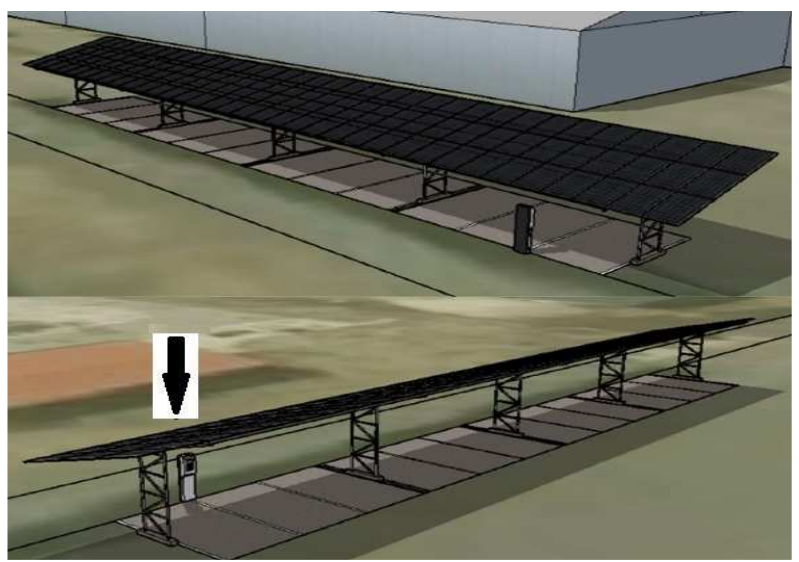

Fig. 9 Charging Station for Electric Mobility

Another area of importance is the green roofs/garden roofs and green facades, systems environmentally friendly. It is one method to capture GHG and to cool indoor building areas, which should be coordinated with exhaust systems near the glass oven where there are high temperature levels [10].

The energy performance of a green roof varies according to the characteristics of the building and the type of roof chosen. This typology of roofs and facades improves thermal insulation, increasing energy efficiency and energy savings. There is a decrease air flows between inside and outside and a temperature difference of $5^{\circ} \mathrm{C}$ with this systems. There will raise the comfort and reduce heating or cooling energy costs. It also improves sound insulation and noise absorption in an industrial environment.

Finally, a system to recover the heat from a natural gas furnace chimney was considered, given that this form of energy is the most consumed in the company (Figure 10). In order to determine the potential heat to be recovered a infrared thermographic analysis in the furnace chimney was previously done [11].

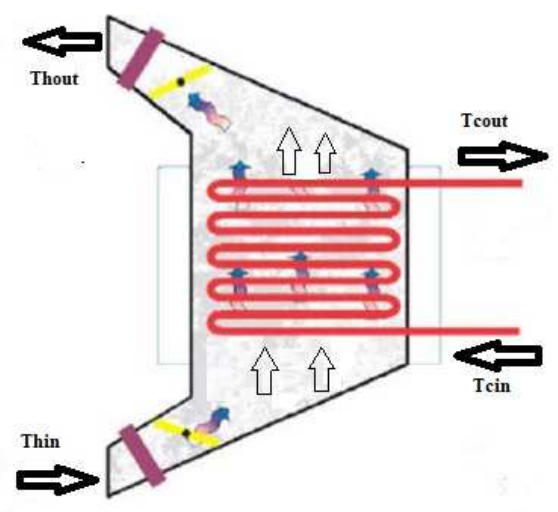

Fig. 10 Heat Exchanger Operation

In this type of industry the furnace must always be in operation. The goal here was to design a system that can take advantage of the heat dissipated in the furnace exhaust (Figure 11).

This heat recovery was conceived using the heat exchanger equipment in the chimney furnace for general heating and for sanitary hot water.

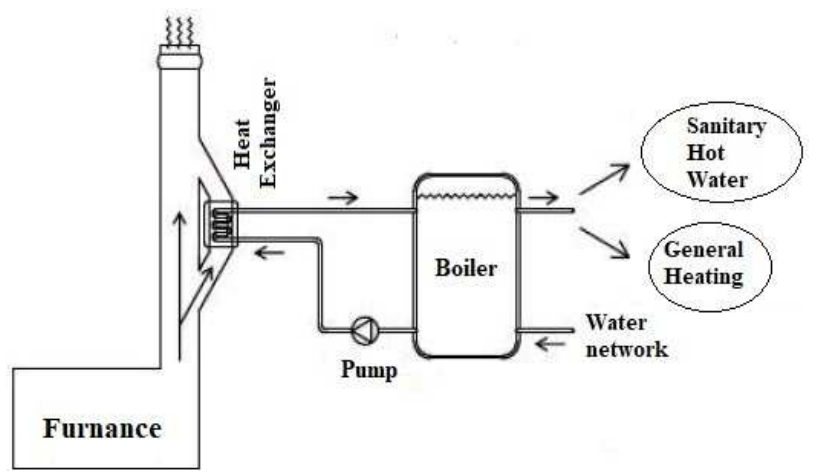

Fig.11 System in Chimney to Recovery the Heat Waste.

\section{Conclusion}

There are a wide range of energy efficiency measures that can be implemented in this type of industry. With this research a new energy model and a high performance of energy efficiency standards were achieved, in conjunction with better energy needs management. As consequence new energy savings will be obtained in the company's financial costs. Other measures implemented are the optimization of lighting, ventilation, air conditioning, compressed air and forklifts. Other 
implementations such as landscaped roofs have also been suggested to retain, in a natural way the GHG emissions in this intensive energy industrial consumer.

\section{Acknowledgement}

This work has been partially supported by the Portuguese Foundation for Science and Technology under the project grant UID/Multi/00308/2019.

\section{References}

[1] Roadmap for Moving to a Competitive Low Carbon Economy in 2050 (CE, 2011)

[2] W. Kahlenborn, S. Kabisch, J. Klein, I. Richter, S. Schürmann, "Energy Management - Systems in Practice: 50001 A guide for Companies and Organisations", (2012). p. 115, (2012)

[3] E.Abdelaziz, R.Saidur, S.Mekhilef, "A Review on Energy Saving Strategies in Industrial Sector" in Renewable and Sustainable Energy Reviews, volume 15, (2011). pp 150-168, see also: https://doi.org/10.1016/j.rser.2010.09.003, accessed January 2019

[4] Vidrexport;/Produção de Vidro, Lda see also: http://www.vidrexport.com

[5] N. Labanca, P. Bertoldi, "Beyond Energy Efficiency and Individual Behaviours: Policy Insights from Social Practice Theories", Energy Policy, Elsevier B.V. volume 115, April 2018, pp 494-502, see also: https://doi.org/10.1016/j.enpol.2018.01.027 accessed December 2018

[6] J. Palm, F. Backman, "Energy Efficiency in SMEs: Overcoming the Communication Barrier" in Energy Efficiency Springer Book, (2020), see also: https://doi.org/10.1007/s12053020-09839-7

[7] J. Azevedo, "Permutadores de Calor/Heat Exchangers", pp. 129, (2005).

[8] PVSyst Photovoltaic Software. see also: https://www.pvsyst.com

[9] Software: SMA Sunny Design. see also: https://www.sunnydesignweb.com/sdweb/\#/Home; accessed May 2019

[10] V. Seifert, J.A.M. da Silva, E. Torres,"Residual Steam Recovery in Oil Refineries: Technical and Economic Analyses" in Energy Efficiency Springer Book, (2019), https://doi.org/10.1007/s12053-018-9731-8

[11] Prudencio, Why Choose Landscaped Roof. see also: https://prudencio.pt/pt/porque-optar-por-coberturas-ajardinadas/ accessed February 2019 